\title{
Correlation between Electrical Conductivity and Microwave Shielding Effectiveness of Natural Rubber Based Composites, Containing Different Hybrid Fillers Obtained by Impregnation Technology
}

\author{
Ahmed A. Al-Ghamdi'1, Omar A. Al-Hartomy'1, Falleh R. Al-Solamy², Nikolay T. Dishovsky ${ }^{3}$, \\ Petrunka Malinova ${ }^{3}$, Nikolay T. Atanasov ${ }^{4,5}$, Gabriela L. Atanasova ${ }^{4,5}$ \\ ${ }^{1}$ Department of Physics, Faculty of Science, King Abdulaziz University, Jeddah, KSA \\ ${ }^{2}$ Department of Mathematics, Faculty of Science, King Abdulaziz University, Jeddah, KSA \\ ${ }^{3}$ Department of Polymer Engineering, University of Chemical Technology and Metallurgy, Sofia, Bulgaria \\ ${ }^{4}$ Department of Telecommunications, Faculty of Telecommunications and Management, University of Telecommunications and Post, \\ Sofia, Bulgaria \\ ${ }^{5}$ Department of Communication and Computer Engineering, Faculty of Engineering, South-West University 'Neofit Rilski', Blagoevgrad, \\ Bulgaria \\ Email:dishov@uctm.edu
}

How to cite this paper: Al-Ghamdi, A.A., Al-Hartomy, O.A., Al-Solamy, F.R., Dishovsky, N.T., Malinova, P., Atanasov, N.T. and Atanasova, G.L. (2016) Correlation between Electrical Conductivity and Microwave Shielding Effectiveness of Natural Rubber Based Composites, Containing Different Hybrid Fillers Obtained by Impregnation Technology. Materials Sciences and Applications, 7, 496-509.

http://dx.doi.org/10.4236/msa.2016.79043

Received: August 7, 2016

Accepted: September 5, 2016

Published: September 8, 2016

\begin{abstract}
The paper presents the synthesis and characterization of carbon black/silicone dioxide hybrid fillers obtained by an impregnation technology. The electromagnetic interference shielding effectiveness of the composites filled with carbon black/silicone dioxide hybrid fillers was measured in wide frequency range of $1-12 \mathrm{GHz}$. The dc and ac electrical conductivity of composites also have been investigated. The relationship between electrical ( $\mathrm{dc}$ and ac) conductivity and shielding effectiveness was analyzed. A positive correlation was found between the absorptive shielding effectiveness and ac conductivity for composites comprising conductive carbon black/silica filler, when the filler loading is above the percolation threshold.
\end{abstract}

\section{Keywords}

Composite Materials, Correlation, Electrical Conductivity, Shielding Effectiveness

\section{Introduction}

Recently, the importance of preventing electromagnetic interference (EMI) on diverse 
Copyright $\odot 2016$ by authors and Scientific Research Publishing Inc. This work is licensed under the Creative Commons Attribution International License (CC BY 4.0).

http://creativecommons.org/licenses/by/4.0/ electronic devices has increased with the rapid development of radiation source and the high reliability requirements for electronic devices [1]. Furthermore, EMI shielding at higher frequency especially microwave radiation has become one of the serious concerns to the society as it not only affects the lifetime, performance of electronic devices but also has adverse effect on human beings [2]. Hence, many efforts have been done to design and develop EMI shielding materials/composites to eliminate the harmful effects of electromagnetic radiation.

Among the various composite materials, rubber composite materials filled with hybrid fillers are also employed as appropriate electromagnetic shields due to their combined electrical conductivity, interesting mechanical and dielectric properties. In the last years, a considerable number of studies investigated the application of rubber composite materials as EMI shields and radar absorbing materials [3]-[9]. In order to achieve high value of shielding effectiveness of conductive composites, non-conductive fillers such as $\mathrm{SiO}_{2}$, are used [10] [11]. For example, Mishra et al. [10] found that the phenolic resin sheet consisting of multiphase such as $\mathrm{EG}, \gamma-\mathrm{Fe}_{2} \mathrm{O}_{3}$, silica and carbon fiber exhibits enhanced shielding effectiveness (from 18.77 to $55.40 \mathrm{~dB}$ ) in the frequency range of 8.2 - $12.4 \mathrm{GHz}$ (X-band). However, Xiang et al. [12] used silica particles for fabricating MWCNT-fused silica composites for electromagnetic interference shielding.

There are no literature data on the correlation between electrical conductivity and EMI shielding effectiveness (SE) of natural rubber based (NR) composites loaded with carbon black/silicone dioxide hybrid fillers in wide frequency range of $1-10 \mathrm{GHz}$.

The aim of the paper is to investigate the influence of type of filler and percolation threshold on the correlation between electrical conductivity and shielding effectiveness of natural rubber based composite loaded with three types of hybrid carbon black/silicon dioxide fillers obtained by an impregnation technology using carbon black of different characteristics as a substrate.

\section{Experimental Details}

\subsection{Materials}

Natural rubber SVR 10 (Hong Thanh Rubber Pty. Ltd.) was used as a polymer matrix. The other ingredients such as zinc oxide, stearic acid, N-tert-butyl-2-benzothiazole sulfenamide (TBBS) and sulphur were commercial grades and used without further purification. Industrial furnace carbon black types PM-15 and PM-75 (produced in Russia with characteristics corresponding to those of carbon black types N 776 and N 330, respectively) and conductive carbon black Printex XE-2B (Orion Engineered Carbons $\mathrm{GmbH}$ ) were used as substrates for production of the hybrid fillers. Silicasol (containing $40 \%$ of silica; $\mathrm{pH}-9$; density $1.3 \mathrm{~g} / \mathrm{cm}^{3}$ ) was chosen as an impregnating agent due to our idea to obtain carbon/silica dual-phase fillers. The choice of these three fillers was caused by the big difference in their main characteristics: specific surface area, particle size, oil absorption number, iodine adsorption, etc.

\subsubsection{Hybrid Fillers Preparation}

The hybrid fillers were prepared via impregnation according to following procedure: 
A mixture of $100 \mathrm{~g}$ of furnace carbon black (PM-15 or PM-75) or Printex XE-2B carbon black and the needed amount of silicasol, corresponding to $3 \%$ or $7 \%$ of silica, was placed into a ball mill and $1.6 \mathrm{~L}$ of distilled water was poured over it. The impregnation and homogenization were run for $2 \mathrm{~h}$. After the impregnation, the fillers with substrate PM-75 and PM-15 were dried at $50^{\circ} \mathrm{C}$ for $30 \mathrm{~min}$ and then at $200^{\circ} \mathrm{C}$ for 2 hours. Fillers with substrate Printex XE-2B were placed into a drying chamber at $150^{\circ} \mathrm{C}$ and the drying continued for than 2 hours until complete dryness of the compound. After that, the product was ground in a ball mill for 2 hours. Then it was thermally treated at $440^{\circ} \mathrm{C}$ under $10^{-2} \mathrm{~mm} \mathrm{Hg}$ vacuum for 2 hours in a reactor designed especially for the purpose.

The obtained hybrid fillers were denoted as, PM-15-3, PM-15-7, PM-75-3, and PM-75-7, for fillers with furnace CB. The last digit denotes the percentage of silica they comprise. The hybrid fillers with conductive carbon black (CCB) were denoted as CCB-3, and CCB-7, respectively. The substrates were denoted as PM-15-0, PM-75-0, and CCB-0, respectively. The amounts of filler are expressed in phr (parts in wt per 100 parts in wt of dry rubber) in the following sections.

\subsubsection{Preparation of Rubber Composites}

The compositions of rubber-based composites are summarized in Table 1 . The mixing of rubber compounds was performed in two-roll laboratory mill with rolls dimensions $\mathrm{L} / \mathrm{D} 320 \mathrm{~mm} \times 160 \mathrm{~mm}$ and 1.27 friction. The speed of the slow roll was $25 \mathrm{~min}^{-1}$.

The vulcanization of the NR based compounds was carried out on an electrically heated hydraulic press with a special homemade mold at $150^{\circ} \mathrm{C}$ and $10 \mathrm{MPa}$. Finally, thin sheets (dimensions $150 \mathrm{~mm} \times 150 \mathrm{~mm}$, thickness $2 \mathrm{~mm}$ ) of vulcanized rubber compounds were obtained.

Table 1. Composition of the investigated rubber compounds (phr).

\begin{tabular}{cccccccccc}
\hline & NR1 & NR2 & NR3 & NR4 & NR5 & NR6 & NR7 & NR8 & NR9 \\
\hline $\begin{array}{c}\text { Natural Rubber } \\
\text { SVR 10 }\end{array}$ & 100.0 & 100.0 & 100.0 & 100.0 & 100.0 & 100.0 & 100.0 & 100.0 & 100.0 \\
Zinc Oxide & 3.0 & 3.0 & 3.0 & 3.0 & 3.0 & 3.0 & 3.0 & 3.0 & 3.0 \\
Steric Acid & 2.0 & 2.0 & 2.0 & 2.0 & 2.0 & 2.0 & 2.0 & 2.0 & 2.0 \\
PM-15-0 & 70.0 & - & - & - & - & - & - & - & - \\
PM-15-3 & - & 70.0 & - & - & - & - & - & - & - \\
PM-15-7 & - & - & 70.0 & - & - & - & - & - & - \\
PM-75-0 & - & - & - & 70.0 & - & - & - & - & - \\
PM-75-3 & - & - & - & - & 70.0 & - & - & - & - \\
PM-75-7 & - & - & - & - & - & 70.0 & - & - & - \\
CCB-0 & - & - & - & - & - & - & 70.0 & - & - \\
CCB-3 & - & - & - & - & - & - & - & 70.0 & - \\
CCB-7 & - & - & - & - & - & - & - & - & 70.0 \\
TBBS & 1.5 & 1.5 & 1.5 & 1.5 & 1.5 & 1.5 & 1.5 & 1.5 & 1.5 \\
Sulfur & 2.0 & 2.0 & 2.0 & 2.0 & 2.0 & 2.0 & 2.0 & 2.0 & 2.0 \\
\hline
\end{tabular}


Composites comprising fillers PM-15-0, PM-75-0, CCB-0 in the concentration range 10 - 60, 80 and 90 (phr) were also prepared in order to establish the percolation threshold of the composites filled with different types of carbon black. However, the former composites are not included in Table 1 because their properties were not determined except for the dc conductivity.

\subsection{Measurements}

\subsubsection{Volume Resistivity Measurements}

Volume resistivity $\left(\rho_{V}\right.$ in $\Omega \cdot \mathrm{m}$ ) of the obtained flat rubber based composites was measured using two electrodes method and calculated by Equation (1)

$$
\rho_{v}=R_{v} S / h
$$

where:

$R_{V}$ is ohmic resistance between the electrodes; $h$-sample thickness between the electrodes, in $\mathrm{m}$; and $S$-cross sectional area of the measuring electrodes, in $\mathrm{m}^{2}$.

The dc electrical conductivity of the composites was calculated using Equation (2)

$$
\sigma_{d c}=1 / \rho_{v} .
$$

\subsubsection{AC Electrical Conductivity Measurement}

AC electrical conductivity, which is associated with dielectric loss factor $\varepsilon^{\prime \prime}$, was calculated using Equation (3)

$$
\sigma_{a c}=\omega \varepsilon=2 \pi f \varepsilon_{0} \varepsilon_{r}^{\prime \prime}
$$

where $f$ is the frequency of electromagnetic field, in $\mathrm{Hz}, \varepsilon_{0}=8.854 \times 10^{-12}(\mathrm{~F} / \mathrm{m})$ is the permittivity of free space, and $\varepsilon_{r}^{\prime \prime}=\varepsilon^{\prime \prime} / \varepsilon_{0}$ [13]. The measurements of the real $\varepsilon^{\prime}$ and imaginary $\varepsilon$ "parts of permittivity of composites were carried out by using the resonant perturbation method.Accordingto the resonant perturbation method, the tested sample is introducedinto a resonator, and the electromagnetic parameters of the sampleare deduced from the changein the resonant frequency and quality factor of the resonator [14].

\subsubsection{Shielding Effectiveness Measurement}

The EMI shielding effectiveness of rubber composites was analyzed using the measurement setup indicated in Figure 1 in frequency range from $1 \mathrm{GHz}$ to $12 \mathrm{GHz}$. Composite samples of $2 \mathrm{~mm}$ thickness were used.

According to classical electromagnetic wave theory [15] [16], the total shielding effectiveness $\left(S E_{T}\right)$ of a composite is expressed in terms of the ratio of the incident power on the composite surface $P_{I}$ and the transmitted power $P_{T}$, and can be mathematically expressed in logarithmic scale, in $\mathrm{dB}$ as

$$
S E_{T}=10 \log _{10}\left(P_{I} / P_{T}\right)=S E_{R}+S E_{A}+S E_{M}
$$

where $S E_{R}$ and $S E_{A}$ represents the contributions in total shielding effectiveness due to reflection and absorption, respectively, $S E_{M}$ represents the additional effects of multiple reflections and transmissions [15] and can be neglected [17] in all practical application 


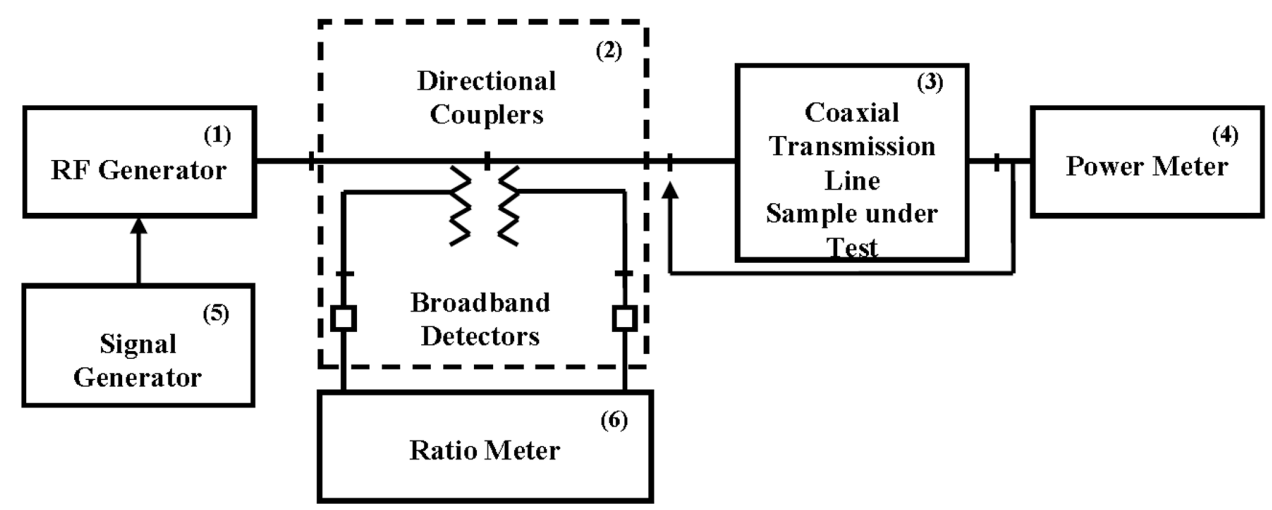

Figure 1. Schematic diagram of the system for measuring EMI SE. (1) A set of radiofrequency generators G4-37A, G4-79 to G4-82 and HP 68A; (2) A coaxial reflectometer; (3) A coaxial transmission line Orion type $\mathrm{E} 2 \mathrm{M}$ for frequencies from $1 \mathrm{GHz}$ to $5 \mathrm{GHz}$ and a coaxial transmission line APC-7 mm for frequencies from $6 \mathrm{GHz}$ to $12 \mathrm{GHz}$; (4) A power meter HP 432A; (5) A signal generator BM492 releasing a modulating signal at $1 \mathrm{kHz}$ and (6) ratio meter HP Model 416A.

when $S E_{T}>10 \mathrm{~dB}[10]$.

The total shielding effectiveness $\left(S E_{T}\right.$, in $\left.\mathrm{dB}\right)$ and the reflective shielding effectiveness of the composite surface $\left(S E_{R}\right.$, in $\left.\mathrm{dB}\right)$ were determined by Equations (5) and (6) [15] [16] [18].

$$
S E_{T}=-10 \log _{10} T
$$

where: $T=\left|P_{T} / P_{I}\right|=\left|S_{21}\right|^{2}$

$$
S E_{R}=-10 \log _{10}(1-R)
$$

where $R=\left|P_{R} / P_{I}\right|=\left|S_{11}\right|^{2}, S_{11}$ and $S_{21}$ are complex scattering parameters or $S$-parameters $\left(S_{11}\right.$ corresponds to the reflection coefficient and $S_{21}$ - to the transmission coefficient).

To determine the shielding components for the composites, $P_{I}, P_{T}$ and $|\Gamma|=\left|S_{11}\right|$ were measured, and $P_{R}$ was computed from the magnitude of reflection coefficient $\left(P_{R}=|\Gamma|^{2} P_{I}\right)$.

The absorptive shielding effectiveness $\left(S E_{A}\right.$ in $\left.\mathrm{dB}\right)$ was calculated as the difference between Equations (5) and (6), as shown in Equation (7).

$$
S E_{A}=S E_{T}-S E_{R}
$$

\subsection{Statistical Analysis}

IBM SPSS Statistics software was used for data processing and statistical analysis. Pearson's correlation coefficient was used to analyze the correlation between ac conductivity and EMI SE in frequency range from $1 \mathrm{GHz}$ to $10 \mathrm{GHz}$. Significance was defined at a level of $\mathrm{P}<0.05$.

\section{Results and Discussion}

\subsection{Electrical Properties}

The dc electrical conductivity of rubber composites comprising fillers PM-15-0, PM-75- 
0 , CCB- 0 as a function of filler loading is shown in Figure 2. It is observed from these results that for all composites, the dc electrical conductivity increases with the increase in carbon black loading. When the carbon black loading reaches a level sufficient for the aggregates to form a continuous network, the electrical conductivity of the rubber compound arises significantly (several orders of magnitude). This mechanism is a part of the foundation of the percolation theory [19].

The carbon black loading at which the conductivity starts to increase rapidly is about $10 \mathrm{phr}$ for Printex XE-2B and as much as $70 \mathrm{phr}$ for PM-15. In the case of carbon black PM-75 the conductivity starts to increase after filler loading of $30 \mathrm{phr}$, but at $70 \mathrm{phr}$ the increase continues. For conductive carbon black Printex XE-2B filled composites, the increase of conductivity is quite sharp with initial filler addition to the rubber matrix and the dc conductivity increase is much more drastic compared to that of composites with PM-75 and PM-15. Moreover, as more filler is added to the composite above the percolation threshold, the dc electrical conductivity continues to increase but slowly. Finally, after $60 \mathrm{phr}$ the conductivity constantly retains the same regardless of the increasing content of the filler Printex XE-2B.

The effects of the types of conductivity ( $d c$ versus ac), the percolation threshold, type of the filler, and silica phase in filler on the EMI SE of the rubber composites were assessed at filler loading $70 \mathrm{phr}$. Depending on dc conductivity of the composites at 70 phr filler loading the composites behavior can be defined as: (1) prior to the percolation threshold for composites NR1-NR3 with hybrid fillers PM-15-0, PM-15-3 and PM-15-7, respectively; (2) about the percolation threshold (the percolation has begun but has not been completed yet) for composites NR4-NR6 with hybrid fillers PM-75- 0, PM-75-3 and PM-75-7, respectively and (3) above the percolation threshold for composites NR7-NR9 with hybrid fillers CCB-0, CCB-3 and CCB-7, respectively.

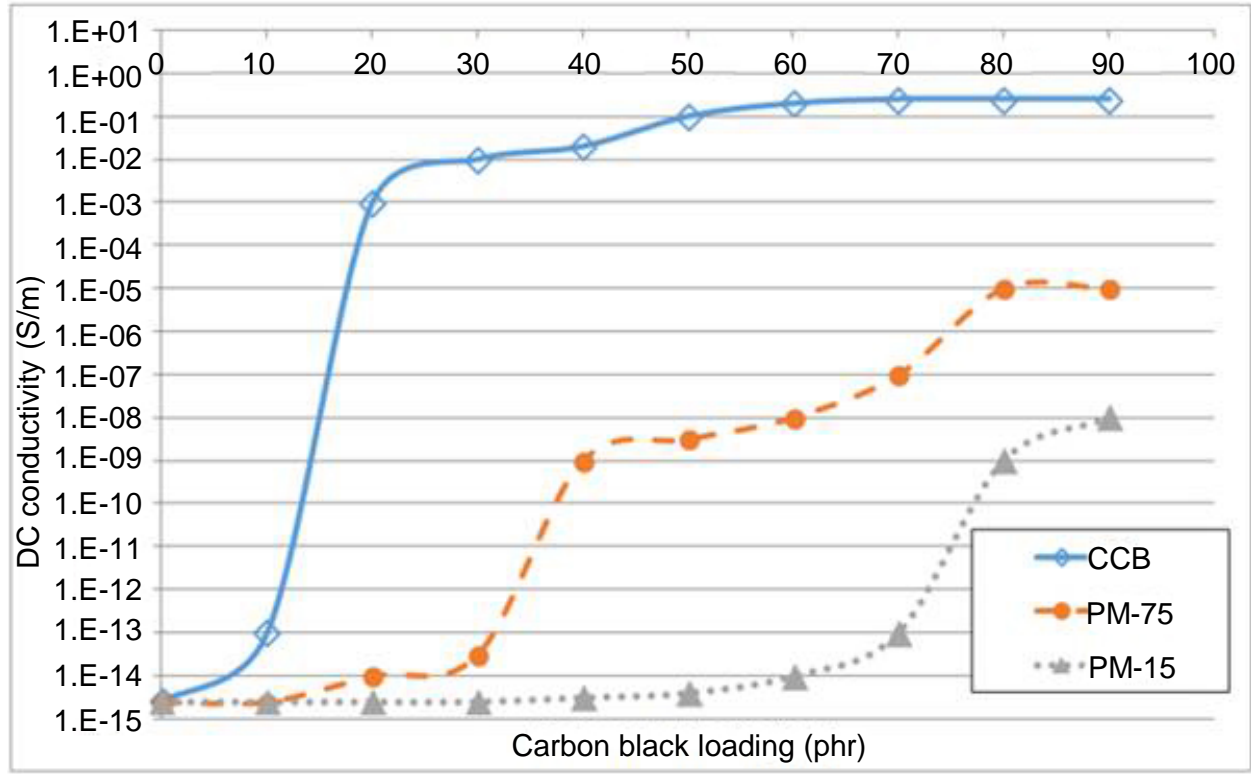

Figure 2. DC electrical conductivity of natural rubber composites as a function of filler loading. 
Table 2 presents the influence of silica phase in hybrid fillers on the dc electrical conductivity for the studied composites. As shown in Table 2, there is a direct correlation between increasing $\mathrm{SiO}_{2}$ content and dc electrical conductivity of composites.

From the results, we can conclude that increasing silica concentration in filler, the dc electrical conductivity decrease. The decrease of dc electrical conductivity in the composites may be due to the formation of isolated segregated regions. This effect is most expressive at composites with filler PM-15, from $3.3 \times 10^{-13}$ to $8.3 \times 10^{-14} \mathrm{~S} / \mathrm{m}$.

The well pronounced difference in $\mathrm{dc}$ conductivity values for the composites is due to the difference in the size of carbon black particles and consequently to the difference in the their specific surface area. The specific surface area of furnace carbon black PM$15-0$ is $15 \mathrm{~m}^{2} / \mathrm{g}$, PM-75-0 is $75 \mathrm{~m}^{2} / \mathrm{g}$, that of CCB-0-1000 m²/g. The smaller particles of Printex XE-2B i.e. their higher specific surface area, favours the formation of conductive pathways, even at lower filler concentrations that is a prerequisite for higher conductivity.

\subsection{Shielding Effectiveness}

EMI shielding effectiveness of NR based composites (NR1-NR9) was investigated in a wide frequency range from $1 \mathrm{GHz}$ to $12 \mathrm{GHz}$ at the level of the filler loading $70 \mathrm{phr}$ as given in Table 1.

As can be seen from Figures 3-5 the NR composites with hybrid filler based on furnace carbon black possessed shielding effectiveness due to both reflection and absorption. $\mathrm{EMI} \mathrm{SE}_{\mathrm{T}}$ of composites with conductive carbon black is mainly due to absorption. EMI SE of all composites shows wave like variation against frequency.

Table 2. DC electrical conductivity of the investigated composites.

\begin{tabular}{cccccccccc}
\hline Composite & NR1 & NR2 & NR3 & NR4 & NR5 & NR6 & NR7 & NR8 & NR9 \\
$\sigma_{\mathrm{DC}}(\mathrm{S} / \mathrm{m})$ & $3.3 \times 10^{-13}$ & $2.4 \times 10^{-13}$ & $8.3 \times 10^{-14}$ & $4.6 \times 10^{-7}$ & $3.3 \times 10^{-7}$ & $2.6 \times 10^{-7}$ & 0.44 & 0.28 & 0.23 \\
\hline
\end{tabular}

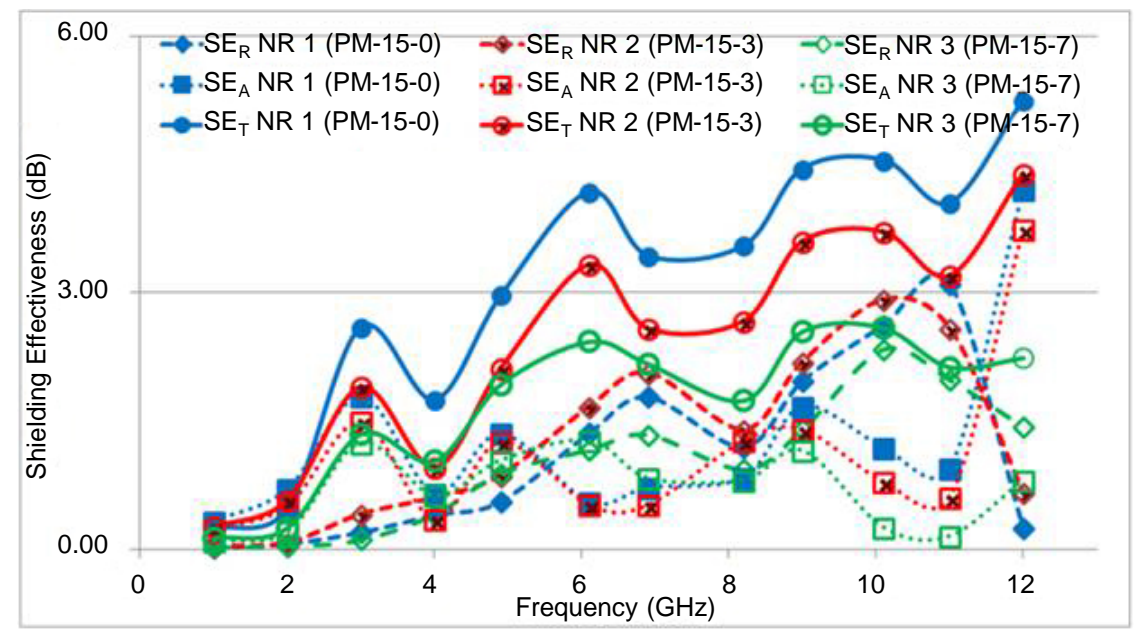

Figure 3. Shielding effectiveness ( $\mathrm{SE}_{\mathrm{R}}, \mathrm{SE}_{\mathrm{A}}$, and $\mathrm{SE}$ ) versus frequency for natural rubber composites NR1-NR3. 


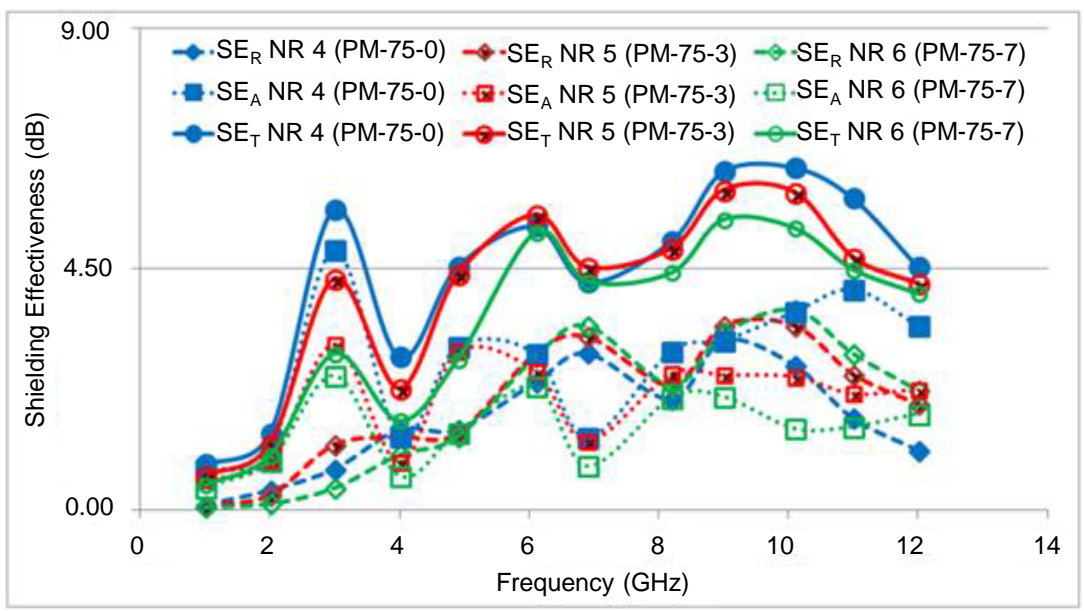

Figure 4. Shielding effectiveness $\left(\mathrm{SE}_{\mathrm{R}}, \mathrm{SE}_{\mathrm{A}}\right.$, and $\left.\mathrm{SE}_{\mathrm{T}}\right)$ versus frequency for natural rubber composites NR4-NR6.

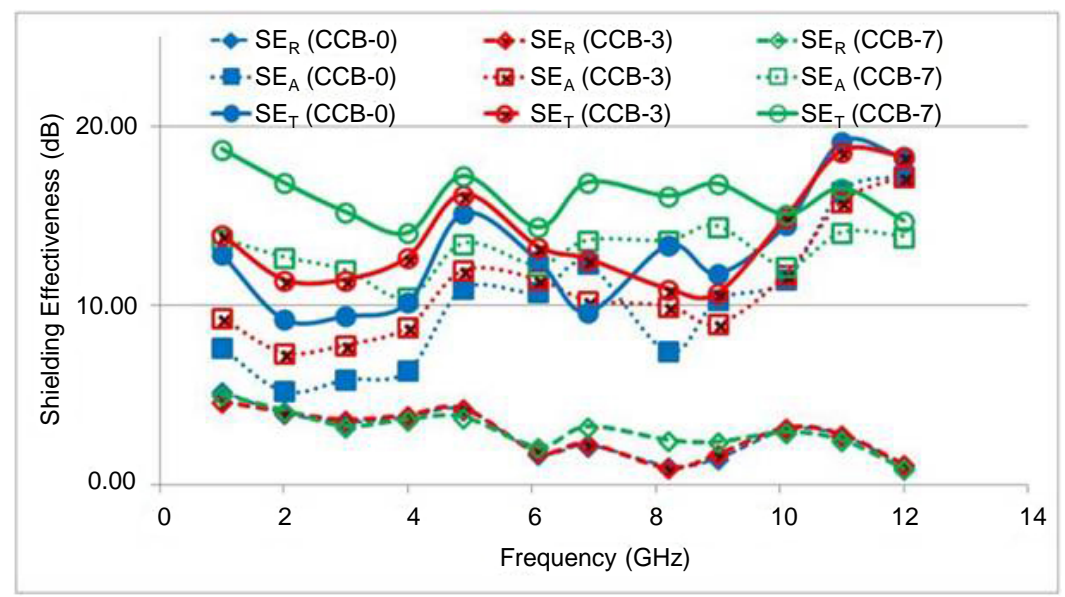

Figure 5. Shielding effectiveness $\left(\mathrm{SE}_{\mathrm{R}}, \mathrm{SE}_{\mathrm{A}}\right.$, and $\left.\mathrm{SE}_{\mathrm{T}}\right)$ versus frequency for natural rubber composites NR7-NR9.

The effect of frequency on EMI SE of NR based composites could be estimated by the dynamic range of SE (difference between the maximum and minimum value in $d B$ ). The dynamic range and mean value of EMI SE (total, absorptive and reflective), and standard deviation for all composites in frequency range of $1 \mathrm{GHz}$ to $12 \mathrm{GHz}$ are reported in Table 3.

It is clearly visible (for all composites) that addition of silica to the matrix of the composite narrows its $\mathrm{SE}_{\mathrm{A}}$ dynamic range. Furthermore, EMI $\mathrm{SE}$ exhibits large differences for different composites across the measured frequency range. For example, the mean value of EMI total shielding effectiveness (Table 3) obtained for composites with furnace carbon black is between $1.71-3.13 \mathrm{~dB}$ (PM-15) and 3.50 - $4.42 \mathrm{~dB}$ (PM-75) at loading of $70 \mathrm{phr}$, whereas for composites with Printex XE-2B the value is between $12.99 \mathrm{~dB}$ and $16.06 \mathrm{~dB}$ at the same loading. The variation of $\mathrm{EMI} \mathrm{SE}_{\mathrm{T}}$ is related to the composite structure and the hybrid fillers properties. The higher EMI SE for the 
Table 3. Dynamic range and mean value of EMI SE in frequency range from $1 \mathrm{GHz}$ to $12 \mathrm{GHz}$.

\begin{tabular}{cccccccccc}
\hline & NR1 & NR2 & NR3 & NR4 & NR5 & NR6 & NR7 & NR8 & NR9 \\
\hline SE $_{\mathrm{T}}$ dynamic range (dB) & 6.0 & 5.0 & 3.0 & 7.0 & 6.0 & 6.0 & 11.0 & 9.0 & 5.0 \\
SE $_{\text {A dynamic range (dB) }}$ & 5.0 & 4.0 & 1.5 & 5.0 & 4.0 & 3.0 & 13.0 & 11.0 & 5.0 \\
SE $_{\text {R dynamic range (dB) }}$ & 4.0 & 3.0 & 2.3 & 4.0 & 4.0 & 4.0 & 5.0 & 5.0 & 6.0 \\
$\mathrm{SE}_{\mathrm{T}}$ Mean value (dB) & 3.13 & 2.44 & 1.71 & 4.42 & 4.06 & 3.50 & 12.99 & 13.75 & 16.06 \\
\pm S.D (dB) & \pm 1.60 & \pm 1.32 & \pm 0.85 & \pm 1.82 & \pm 1.76 & \pm 1.70 & \pm 3.31 & \pm 2.74 & \pm 1.37 \\
$\mathrm{SE}_{\mathrm{A}}$ Mean value (dB) & 1.25 & 1.06 & 0.71 & 2.73 & 2.03 & 1.51 & 10.16 & 10.79 & 13.08 \\
\pm S.D (dB) & \pm 1.04 & \pm 0.95 & \pm 0.43 & \pm 1.31 & \pm 0.87 & \pm 0.69 & \pm 3.89 & \pm 3.00 & \pm 1.14 \\
$\mathrm{SE}_{\mathrm{R}}$ Mean value (dB) & 1.13 & 1.29 & 1.01 & 1.69 & 2.02 & 1.99 & 2.73 & 2.86 & 3.03 \\
\pm S.D (dB) & \pm 1.00 & \pm 0.99 & \pm 0.75 & \pm 0.99 & \pm 1.17 & \pm 1.34 & \pm 1.36 & \pm 1.27 & \pm 1.07 \\
\hline
\end{tabular}

composites comprising conductive carbon black Printex XE-2B and the hybrid fillers on its base is related to the higher electrical conductivity of these composites. As known from the general EMI theory, (15) when skin depth $\delta$ becomes much less as compared to actual shield thickness $t$, which is valid in our case, EMI $\mathrm{SE}_{\mathrm{T}}$ increases with the increase in total electrical conductivity $\sigma$, as shown in Equations (8) and (9) [15]. In these equations, it is apparent that both the shielding by reflection $\mathrm{SE}_{\mathrm{R}}$ and shielding by absorption $\mathrm{SE}_{\mathrm{A}}$ increases with the increase in the electrical conductivity [20]. In the equations, $\mu$ is the permeability, $\mu_{r}$ is the relative permeability, and $\omega=2 \pi f$ is the angular frequency. The term total electrical conductivity $(\sigma)$ which is composed of frequency dependent (ac) and independent (dc) components is presented in Equation (10) as:

$$
\begin{gathered}
S E_{R}=10 \log _{10}\left(\frac{1}{16} \frac{\sigma}{\omega \mu_{r} \varepsilon_{0}}\right)=39.5+10 \log _{10}\left(\frac{\sigma}{2 \pi f \mu}\right) \\
S E_{A}=8.686 t \sqrt{\pi f \mu \sigma} \\
\sigma=\sigma_{d c}+\sigma_{a c}
\end{gathered}
$$

It is observed from Table 3 and Figure 2 that the EMI SE has some dependence on percolation threshold. The composites prior to the percolation threshold (NR1-NR3) have the lowest $\mathrm{SE}_{\mathrm{T}}$ values, while those with loading above the percolation threshold (NR7-NR9) have the highest ones. In between are the composites (NR4-NR6) where in the percolation has started but has not been completed yet. Hence, conductive mesh formation and type of hybrid filler decide the EMI SE of a particular composite.

\subsection{Correlation between DC Electrical Conductivity and EMI SE}

The correlation between the mean values of EMI SE (total, absorptive and reflective) and dc electrical conductivity of NR based composites loaded with hybrid fillers is displayed in Figure 6. It is found that $\mathrm{EMI} \mathrm{SE}_{\mathrm{T}}$ and $\mathrm{SE}_{\mathrm{A}}$ increase with dc conductivity of composites comprising furnace carbon black and the hybrid fillers on its base.

A positive correlation is observed between the EMI SE $\left(\mathrm{SE}_{\mathrm{T}}\right.$ and $\left.\mathrm{SE}_{\mathrm{A}}\right)$ and dc conductivity of composites comprising furnace carbon black and the hybrid fillers on its base. However, the correlation is found to be negative with respect to EMI SE ( $\mathrm{SE}_{\mathrm{T}}$ and $\mathrm{SE}_{\mathrm{A}}$ ) 


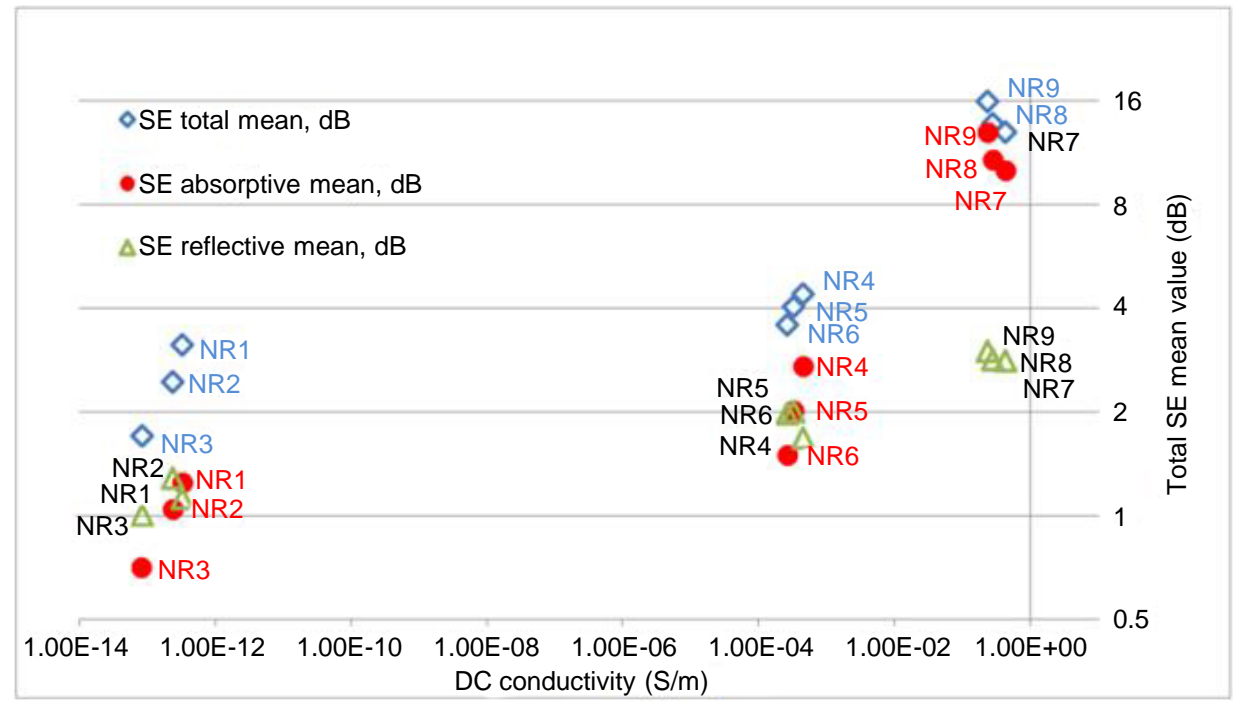

Figure 6. Correlation between EMI shielding effectiveness and dc electrical conductivity of composites NR1-NR9 filled with different silica concentration.

and dc conductivity of composites comprising conductive carbon black Printex XE-2B and the hybrid fillers on its base. This signifies that $\mathrm{dc}$ conductivity is not only the determining factor for controlling the magnitude of shielding effectiveness, but also some other factors play a significant role. For better comprehension of the shielding effectiveness of the composites comprising hybrid fillers with different phase ratios their ac electrical conductivity has been studied in $1 \mathrm{GHz}$ to $10 \mathrm{GHz}$ frequency range and statistical analysis of the data was performed.

\subsection{Correlation between AC Electrical Conductivity and EMI SE}

Table 4 presents the mean value and standard deviation of ac electrical conductivity for composites NR4-NR9. Data about composites NR1-NR3 are not presented as they have mean value of absorptive shielding effectiveness lower than $1.5 \mathrm{~dB}$ in frequency range from $1 \mathrm{GHz}$ to $12 \mathrm{GHz}$.

The result shows that at the same loading ( $70 \mathrm{phr}$ ) electrical (ac and dc) conductivity of NR7, NR8 and NR9 is higher than of NR4, NR5 and NR6, what explains the average $\mathrm{SE}_{\mathrm{T}}$ values for the composites filled with Printex XE-2B which are higher with $10 \mathrm{~dB}$ than those for the composites filled with furnace carbon black.

As seen from the Table 4, ac electrical conductivity is increasing with the increase in silica amount, which is contrary to dc conductivity measurements, where conductivity decreases in all composites. The expected reason for enhance of the ac electrical conductivity of the composites is presence of silica that affected the permittivity of composites. As Equation (3) shows, the ac conductivity is a direct function of dielectric loss. Therefore, incorporation of high permittivity particles like silica with conducting matrix is expected to enhance dielectric loss in wide frequency range. The dielectric losses in a multiphase composite are results of complex phenomena [10]. The existence of interface between the hybrid filler and the rubber matrix, and on the other hand between 
Table 4. Mean value of ac electrical conductivity of the NR composites in frequency range from 1 $\mathrm{GHz}$ to $10 \mathrm{GHz}$.

\begin{tabular}{ccccccc}
\hline Composite & NR4 & NR5 & NR6 & NR7 & NR8 & NR9 \\
\hline Mean value of ac conductivity & 0.0027 & 0.0040 & 0.0054 & 6.158 & 8.305 & 9.916 \\
\pm S.D. (S/m) & \pm 0.003 & \pm 0.0071 & \pm 0.0102 & \pm 6.897 & \pm 8.649 & \pm 9.952 \\
\hline
\end{tabular}

the two phases of the hybrid filler are responsible for interfacial polarization, which further contribute to dielectric loss. Thus, interfacial polarization, as well as the number of possible relaxation modes can produce enhancement of microwave absorption, increased EMI SE, respectively.

The relationship between ac electrical conductivity and EMI SE (reflective, absorptive and total) was analyzed by Pearson's correlation coefficient. Table 5 presents the results of correlation coefficients between $\sigma_{\mathrm{ac}}$ and $\mathrm{SE}_{\mathrm{R}}, \mathrm{SE}_{\mathrm{A}}$ and $\mathrm{SE}_{\mathrm{T}}$ at ten frequencies in the $1 \mathrm{GHz}$ to $10 \mathrm{GHz}$ frequency range.

The highest correlation ( 0.825 for NR7; 0.826 for NR8 and 0.725 for NR9) in a positive direction has been established between absorptive shielding effectiveness and ac electrical conductivity, when the composite is loaded above the percolation threshold. Significant to high correlation has also been observed when total shielding effectiveness and ac electrical conductivity of composites NR7, NR8 and NR9 are compared. The composites filled with furnace carbon black have a correlation of -0.722 (NR4), -0.602 (NR5) and -0.506 (NR6) when their absorptive shielding effectiveness and ac electrical conductivity are compared. We can say that they are correlated significantly in a negative direction. For those composites the lowest correlation from medium to significant has been established between reflective shielding effectiveness and ac electrical conductivity. The direction of the correlation is negative.

From these results, it is concluded that EMI shielding effectiveness of rubber composites comprising carbon black/silica hybrid fillers is primarily affected by the percolation behavior of composites. Below the percolation threshold, the conductivity change is negligible and the conductivity of the composites is equal to the polymer conductivity or slightly higher [21]. An increase in filler loading second phase (silica) results in decrease of EMI shielding effectiveness. This is due to absence of contact between the filler particles. Above the percolation threshold, the dc electrical conductivity increases to the maximum value. An increase in filler loading second phase (silica) results in increase of EMI shielding effectiveness. This is due to the increase in ac electrical conductivity, as shown in Table 4. This observation was also reported by others [11] [12]. Wu et al. [11] found that introducing non-conductive particle into conductive filler filled composites could result in a better conductivity. Hence, silica is also act as a shield when it is used with different materials [10]. Therefore, in the case of natural rubber composite loaded with hybrid carbon black/silica filler the enhance of ac electrical conductivity due to increase filler loading second phase (silica) can play its role for shielding by absorption $\mathrm{SE}_{\mathrm{A}}\left(\mathrm{SE}_{\mathrm{A}}\right.$ mechanism) only when a percolation network is formed. 
Table 5. Person's correlation coefficients between shielding effectiveness with ac electrical conductivity of natural rubber composites.

\begin{tabular}{|c|c|c|c|c|c|c|c|}
\hline \multirow{2}{*}{$\begin{array}{l}\text { Shielding } \\
\text { Mechanism }\end{array}$} & & \multicolumn{6}{|c|}{ AC electrical conductivity to Shielding Effectiveness } \\
\hline & & NR4 & NR5 & NR6 & NR7 & NR8 & NR9 \\
\hline $\begin{array}{l}\text { Total Shielding } \\
\text { Effectiveness }\end{array}$ & $\begin{array}{c}\text { Pearson } \\
\text { Correlation }\end{array}$ & -0.755 & -0.816 & -0.679 & 0.788 & 0.499 & 0.821 \\
\hline $\begin{array}{l}\text { Absorptive Shielding } \\
\text { Effectiveness }\end{array}$ & $\begin{array}{l}\text { Pearson } \\
\text { Correlation }\end{array}$ & -0.722 & -0.602 & -0.506 & 0.825 & 0.826 & 0.725 \\
\hline $\begin{array}{l}\text { Reflective Shielding } \\
\text { Effectiveness }\end{array}$ & $\begin{array}{l}\text { Pearson } \\
\text { Correlation }\end{array}$ & -0.496 & -0.781 & -0.599 & -0.791 & -0.350 & -0.005 \\
\hline
\end{tabular}

\section{Conclusions}

The role of type of filler and percolation threshold on the correlation between electrical conductivity ( $\mathrm{dc}$ and $\mathrm{ac}$ ) and shielding effectiveness of natural rubber based composite loaded with three types of hybrid carbon black/silicon dioxide fillers obtained by an impregnation technology using carbon black of absolutely different characteristics as a substrate has been discussed thoroughly. It has been observed that EMI shielding effectiveness of composites comprising carbon black/silica hybrid fillers is primarily affected by the percolation behaviour of composites. A positive correlation is observed between the EMI SE (total and absorptive) and dc electrical conductivity of composites comprising furnace carbon black and the hybrid fillers on its base when the composites are loaded below and about the percolation threshold. The highest correlation ( 0.825 for NR7; 0.826 for NR8 and 0.725 for NR9) in a positive direction has been established between absorptive shielding effectiveness and ac electrical conductivity, when the composites comprising conductive carbon black Printex XE-2B and the hybrid fillers on its base are loaded above the percolation threshold. The results demonstrated that $\mathrm{dc}$ conductivity is not only the determining factor for controlling the magnitude of shielding effectiveness. In addition, the ac conductivity can play its role for shielding effectiveness only when a percolation network is formed. Hence, combination of both electrically conductive filler and dielectric material $\left(\mathrm{SiO}_{2}\right)$ is effective to enhance the electromagnetic wave attenuation (shielding effectiveness) only when a percolation network is formed.

Due to their properties, the composites comprising carbon black Printex XE-2B and the hybrid fillers on its base could be adopted as a material for improving mobile phone antenna radiation efficiency, reducing specific absorption rate in human head induced from phone antenna and as shielding materials in the frequency range of $1-12 \mathrm{GHz}$.

\section{Acknowledgements}

The work is a part of a project, funded by King Abdulaziz University, Saudi Arabia under grant number $\mathrm{MB} / 11 / 12 / 436$. The authors acknowledge the technical and financial support.

\section{References}

[1] Kang, G.-H. and Kim, S.-H. (2014) Electromagnetic Wave Shielding Effectiveness Based on 
Carbon Microcoil-Polyurethane Composites. Journal of Nanomaterials, 1-6. http://dx.doi.org/10.1155/2014/727024

[2] Sambyal, P., Singh, A.P., Verma, M., Gupta, A., Singh, B.P. and Dhawan, S.K. (2015) Designing of MWCNT/Ferrofluid/Flyash Multiphase Composite as Safeguard for Electromagnetic Radiation. Advanced Materials Letters, 6, 585-591.

[3] Sýkora, R., Babayan, V., Usakova, M., Kruzelak, J. and Hudec, I. (2015) Rubber Composite Materials with the Effects of Electromagnetic Shielding. Polymer Composits, 1-7. http://dx.doi.org/10.1002/pc.23490

[4] Barba, A.A., Lamberti, G., d'Amore, M. and Acierno, D. (2006) Carbon Black/Silicone Rubber Blends as Absorbing Materials to Reduce Electro Magnetic Interferences (EMI). Polymer Bulletin, 57, 587-593. http://dx.doi.org/10.1007/s00289-006-0598-Z

[5] Feng, Y., Qiu, T., Li, X. and Shen, C. (2007) Microwave Absorption Properties of the Carbonyl Iron/EPDM Radar Absorbing Materials. Journal of Wuhan University of Technology-Materials Science Edition, 22, 266-270.

[6] Al-Ghamdi, A.A., Al-Hartomy, O.A., Al-Solamy, F.R., Dishovsky, N., Malinoiva, P., Atanasova, G. and Atanasov, N. (2016) Conductive Carbon Black/Magnetite Hybrid Fillers in Microwave Absorbing Composites Based on Natural Rubber. Composite Part B, 96, 231241. http://dx.doi.org/10.1016/j.compositesb.2016.04.039

[7] Yong, K.C. (2011) Sulphur-Vulcanised Epoxidised Natural Rubber (ENR)-Carbon Black Blends with Reproducible Electrical Conductivity Behaviour. Journal Rubber Research, 14, 151-166.

[8] Nasr, G.M., Soliman, M.A., Hassan, H.H. and Salem-Gaballah, S.M. (2015) Microwave Shielding and DC Electrical Properties of Carbon Black Loaded Rubber Nano-Composites. Journal of Multidisciplinary Engineering Science and Technology, 2, 1542-1546.

[9] Chandran, S.A., Narayanankutty, S.K. and Mohanan, P. (2011) Microwave Characteristics of Polyaniline Based Short Fiber Reinforced Chloroprene Rubber Composites. PolymerPlastics Technology and Engineering, 50, 453-458. http://dx.doi.org/10.1080/03602559.2010.543229

[10] Mishra, M., Singh, A.P., Sambyal, P., Teotia, S. and Shawan, S.K. (2014) Facile Synthesis of Phenolic Resin Sheets Consisting Expanded Graphite $/ \gamma-\mathrm{Fe}_{2} \mathrm{O}_{3} / \mathrm{SiO}_{2}$ Composite and Its Enhanced Electromagnetic Interference Shielding Properties. Indian Journal of Pure \& Applied Physics, 52, 478-485.

[11] Wu, K., Wu, L., Yang, W., Chai, S., Chen, F. and Fu, Q. (2016) Largely Enhanced Electrical Properties of Polymer Composites via the Combined Effect of Volume Exclusion and Synergy. RSC Advanced, 6, 51900-51907. http://dx.doi.org/10.1039/C6RA10129A

[12] Xiang, C., Pan, Y., Liu, X., Sun, X., Shi, X. and Guo, J. (2005) Microwave Attenuation of Multiwalled Carbon Nanotube-Fused Silica Composites. Applied Physics Letters, 87, Article ID: 123103. http://dx.doi.org/10.1063/1.2051806

[13] Kumar, S.B., Hohn, H., Joseph, R., Hajian, M., Ligthart, L.P. and Mathew, K.T. (2001) Complex Permittivity and Conductivity of Poly Aniline at Microwave Frequencies. Journal of the European Ceramic Society, 21, 2677-2680. http://dx.doi.org/10.1016/S0955-2219(01)00344-2

[14] Chen, L.F., Ong, C.K., Neo, C.P., Varadan, V.V. and Varadan, V.K. (2004) Microwave Electronics: Measurement and Materials Characterization. John Wiley \& Sons, Ltd., Chichester. http://dx.doi.org/10.1002/0470020466

[15] Paul, C.R. (2006) Introduction to Electromagnetic Compatibility. 2nd Edition, John Wiley \& Sons, Inc., Hoboken. 
[16] Ott, H.W. (2009) Electromagnetic Compatibility Engineering. John Wiley \& Sons Inc., Hoboken. http://dx.doi.org/10.1002/9780470508510

[17] Al-Ghamdi, A.A. and El-Tantawy, F. (2010) New Electromagnetic Wave Shielding Effectiveness at Microwave Frequency of Polyvinyl Chloride Reinforced Graphite/Copper Nanoparticles. Composites Part A: Applied Science and Manufacturing, 41, 1693-1701. http://dx.doi.org/10.1016/j.compositesa.2010.08.006

[18] Hernandez, B. (2013) Effect of Graphitic Carbon Nanomodifiers on the Electromagnetic Shielding Effectiveness of Linear Low Density Polyethylene Nanocomposites. PhD Thesis. the Graduate School of Clemson University, Clemson.

[19] Stauffer, D. and Aharony, A. (1992) Introduction to Percolation Theory. Taylor \& Francis, London.

[20] Al-Saleh, M.H. (2016) Electrical EMI Shielding and Tensile Properties of PP/PE Blends Filled with GNP: CNT Hybrid Nanofiller. Synthetic Metals, 217, 322-330.

http://dx.doi.org/10.1016/j.synthmet.2016.04.023

[21] Jithin, J., Sunny, A.T., Mathew, P., Pothen, L.A. and Thomas, S. (2013) Micro and Nano Metal Particle Filled Natural Rubber Composites. In: Thomas, S., Chan, C.H., Pothen, L.A., Joy, J. and Maria, H.J., Eds., Natural Rubber Materials, Vol. 2: Composites and Nanocomposites, Royal Society of Chemistry, Cambridge, Chapter 11, 307-326.

Submit or recommend next manuscript to SCIRP and we will provide best service for you:

Accepting pre-submission inquiries through Email, Facebook, LinkedIn, Twitter, etc.

A wide selection of journals (inclusive of 9 subjects, more than 200 journals)

Providing 24-hour high-quality service

User-friendly online submission system

Fair and swift peer-review system

Efficient typesetting and proofreading procedure

Display of the result of downloads and visits, as well as the number of cited articles

Maximum dissemination of your research work

Submit your manuscript at: http://papersubmission.scirp.org/ 